\title{
APRIMORAMENTOS EM UM MICROSCÓPIO CASEIRO E SUA EFICÁCIA PARA ENSINAR CITOLOGIA BÁSICA
}

\author{
R. G. S. SILVA ${ }^{1}$, F. ROQUE \\ Instituto Federal de Educação, Ciência e Tecnologia de Brasília \\ ORCID ID: https://orcid.org/0000-0002-9306-0365² \\ francisco.roque@ifb.edu.br ${ }^{2}$
}

DOI: $10.15628 /$ holos.2020.9468

\section{RESUMO}

Muitas escolas brasileiras não possuem laboratório completo ou mesmo um microscópio para as aulas de Biologia. Visando minimizar os impactos negativos desse cenário sobre a educação científica, este trabalho adaptou um microscópio caseiro e testou sua eficácia para ensinar citologia básica. Para tanto, foram realizadas duas oficinas compostas de montagem do microscópio adaptado, observação de células e avaliação da eficácia dos procedimentos pedagógicos adotados. Ambas as oficinas foram realizadas em agosto de 2019 nas dependências do Instituto Federal de Brasília. As adaptações propostas tornaram o microscópio caseiro mais prático e funcional, o que facilitou o seu manuseio e a rápida observação das amostras biológicas analisadas. Com relação à eficácia desse recurso para ensinar conceitos citológicos, houve variações de rendimento entre os dois grupos avaliados, sendo que os participantes do ensino médio obtiveram melhores resultados após a oficina. Adicionalmente, verificou-se um maior envolvimento dos participantes devido aos vários questionamentos realizados e a intensa curiosidade e atenção durante as duas oficinas. Por fim, sugere-se a aplicação do presente recurso didático em escolas desprovidas de microscópios para aprimorar a qualidade do ensino científico.

PALAVRAS-CHAVE: Alternativa Didática, Células, Microscopia, Ensino, Reciclagem.

\section{IMPROVEMENTS IN A HOMEMADE MICROSCOPE AND ITS EFFECTIVENESS TO TEACH BASIC CYTOLOGY}

\section{ABSTRACT}

Many Brazilian schools do not have a complete laboratory or even a microscope for Biology classes. In order to minimize the negative impacts of this scenario on science education, this work adapted a homemade microscope and tested its effectiveness to teach basic cytology. Thus, we conducted two workshops composed of assembling the adapted microscope, observing cells and evaluating the effectiveness of the adopted pedagogical procedures. Both workshops were held in August 2019 on the premises of the Federal Institute of Brasília. The proposed adaptations made the homemade microscope more practical and functional, which facilitated its handling and
\end{abstract}

the quick observation of the biological samples analyzed Regarding the effectiveness of this resource to teach cytological concepts, there were variations in performance between the two groups evaluated, with high school participants obtaining better results after the workshop. Additionally, there was a greater involvement of the participants due to the various questions asked and the intense curiosity and attention during the two workshops. Finally, it is suggested the application of the present teaching resource in schools without microscopes to improve the quality of scientific education.

KEYWORDS: Didactic Alternative, Cells, Microscopy, Teaching, Recycling. 


\section{INTRODUÇÃO}

A compreensão das células e dos fenômenos relacionados depende do uso de microscópios, instrumentos responsáveis pela visualização de detalhes imperceptíveis ao olho humano (Purves et al., 2009). A origem desse equipamento é incerta, entretanto, especula-se que tenha sido inicialmente produzido no século XVI pelos holandeses Zacharias e Hans Janssen. Tal microscópio foi resultado da sobreposição de lentes e possuía pouca capacidade de aumento e nitidez (Simmons, 2002; Rothbart, 2007). Um importante marco na história da microscopia foi a obra intitulada Micrographia. Nesse livro de 1665, o inglês Robert Hooke descreveu por meio de desenhos e anotações, cerca de sessenta objetos biológicos, introduziu o termo "células" para descrever os minúsculos compartimentos observados em suas amostras e apresentou melhorias no microscópio acrescentando iluminação artificial e uma lente futuramente chamada de "lente de campo" (Martins, 2011). Por isso, ele é considerado o pai da microscopia e da biologia celular. Após quase dois séculos da invenção do microscópio, o holandês Antonie van Leeuwenhoek apresenta o seu microscópio simples composto por uma só lente. Ele também se tornou popular porque as lentes do seu equipamento, ampliação de aproximadamente 270 vezes (Simmons, 2002), Ihe permitiu observar células vivas pela primeira vez.

Com o passar do tempo os microscópios foram sendo cada vez mais aperfeiçoados. Atualmente é possível encontrar equipamentos profissionais de alta qualidade e capacidade de ampliação (aumento de até 1000 vezes), além de melhores técnicas de fixação e coloração de amostras biológicas. A tecnologia também permitiu o desenvolvimento de microscópios eletrônicos que aumentam cerca de $\mathbf{2 0 0 . 0 0 0}$ vezes determinada amostra obtendo detalhes bem mais precisos. Tal capacidade de ampliação é resultado do emprego de feixes de elétrons ao invés da luz (Galleti, 2003). Como consequência direta desses avanços tecnológicos houve o desenvolvimento da citologia (Valério \& Torresan, 2017), ramo da biologia responsável pelo estudo das células, desde seu funcionamento geral até a estrutura e dinâmica de suas organelas. Dessa forma, esse equipamento tão importante para o estudo de células teve um início simplório que foi fundamental para o desenvolvimento dos microscópios atuais complexos, sofisticados e geralmente caros.

Os altos valores dos equipamentos profissionais, como, por exemplo, o microscópio (Fiscarelli, 2007; Freitas et al., 2008; Wallau et al., 2008), são considerados como uma das principais causas de muitas escolas públicas brasileiras não possuírem laboratórios de ciências para a realização de atividades práticas. Segundo o censo escolar brasileiro de 2018, apenas 11,5\% das escolas de Ensino Fundamental e 44,1\% das escolas de Ensino Médio dispõem de tais instalações (Brasil, 2019). Nesse contexto, a educação científica tende a ser deficiente, o que dificulta a compreensão dos discentes sobre o mundo em que vivemos. 
Na sociedade atual, a citologia fornece incontáveis explicações e soluções para fenômenos naturais aplicados na medicina, agricultura, meio ambiente, etc. Embora o seu ensino seja crucial para a compreensão adequada da atualidade e o exercício da cidadania por parte dos discentes, trata-se de um componente cuja execução demanda materiais didáticos de qualidade para serem utilizados como apoio aos livros e textos (Mori et al., 2016). Diante dos custos elevados dos equipamentos necessários para o ensino significativo de citologia, a elaboração de recursos didáticos alternativos para o ensino dessa temática constitui ação necessária para melhorar o atual quadro da educação científica brasileira nos diferentes níveis de ensino público.

Esforços visando amenizar os impactos negativos do atual cenário da educação científica brasileira são observados em diferentes propostas de microscópios artesanais (Wallau et al., 2008; Sepel, Rocha \& Loreto, 2011; Soga et al., 2017; Silva, Baltar \& Bezerra, 2019). Esses autores apresentam possibilidades simples e criativas de se montar microscópios alternativos capazes de fornecer imagens microscópicas de qualidade razoável, prestando-se ao ensino prático de citologia. Contudo, a eficácia desses microscópios para ensinar conceitos citológicos ainda não foi testada no contexto de sala de aula.

Explorar alternativas adicionais de baixo custo (materiais recicláveis) para a confecção de recursos didáticos (microscópio caseiro) é uma forma de melhorar o ensino científico nas escolas públicas brasileiras. Desse modo, este trabalho teve como objetivo a primorar o microscópio caseiro proposto por Sepel, Rocha e Loreto (2011) e testar sua eficácia para ensinar fundamentos de citologia. Presume-se que a confecção e o uso de um modelo alternativo de microscópio caseiro tornarão as aulas sobre citologia mais eficazes e proveitosas quanto aos seus aspectos pedagógicos, independentemente da natureza do grupo avaliado.

\section{METODOLOGIA}

Para avaliação dos objetivos propostos neste estudo foram produzidos dados quantitativos em oficinas ofertadas para dois grupos distintos de participantes. No geral, as oficinas consistiram na montagem do microscópio aprimorado, observação de estruturas celulares e avaliação do desempenho dos participantes antes e após as intervenções didáticas realizadas.

O primeiro grupo avaliado foi composto por 16 estudantes do curso Técnico em Agropecuária Integrado ao Ensino Médio do Instituto Federal de Brasília (Campus Planaltina), aqui tradados como EMI. A oficina ofertada para esse grupo ocorreu em 20 de agosto de 2019, no Campus Planaltina, Planaltina, Distrito Federal. Esse Campus está localizado na zona rural de Planaltina, na porção nordeste do Distrito Federal. Por isso, muitos alunos residem nas suas dependências ou dependem de transporte público limitado para acessarem a instituição. Trata-se do primeiro Campus do Instituto Federal de Brasília que atualmente oferta cursos de nível técnico 
integrado ao ensino médio (agropecuária), técnico (agropecuária e agroindústria) e superior (licenciatura em biologia e tecnólogo em agroecologia).

O segundo grupo avaliado foi composto por 20 participantes de uma oficina ofertada em 27 de agosto de 2019 durante o ConectaIF 2019. Esse evento é realizado anualmente pelo Instituto Federal de Brasília e em 2019 foi realizado no Campus Brasília dessa instituição. Suas atividades, inclusive as oficinas, foram abertas para diversos públicos, desde estudantes do ensino médio, graduandos e professores da instituição até membros da comunidade externa. Por se tratar de um público heterogêneo, o grupo avaliado nessa oficina foi considerado representativo de vários níveis de ensino.

As duas oficinas tiveram como base o microscópio caseiro proposto por Sepel, Rocha e Loreto (2011). Esse recurso didático é feito a partir de materiais recicláveis, tais como uma garrafa pet, uma lente derivada de restos de equipamentos eletrônicos (webcam, por exemplo) e uma fita adesiva transparente. A metade superior de uma garrafa pet funciona como o corpo do microscópio e essa parte foi confeccionada conforme proposta original. O modelo proposto nesta pesquisa, por sua vez, teve a lente fixada mecanicamente na tampa da garrafa em um furo de tamanho equivalente às dimensões da lente usada (Figura 01A) e, ao invés de fita adesiva no bocal da garrafa, foi empregado uma placa fixa de resina de poliéster cristal transparente (Figura 01B). Neste estudo, tal placa foi produzida diretamente no bocal de garrafas invertidas em uma placa plana de vidro conforme descrito a seguir. Em cada garrafa foi depositado cuidadosamente uma fina camada $( \pm 0,5$ $\mathrm{cm}$ de espessura) da mistura resultante de $100 \mathrm{ml}$ de resina de poliéster líquida com quinze gotas de catalizador (responsável pela solidificação da resina). Após um dia de secagem, esse componente do microscópio estava pronto para uso (Figura 01C).

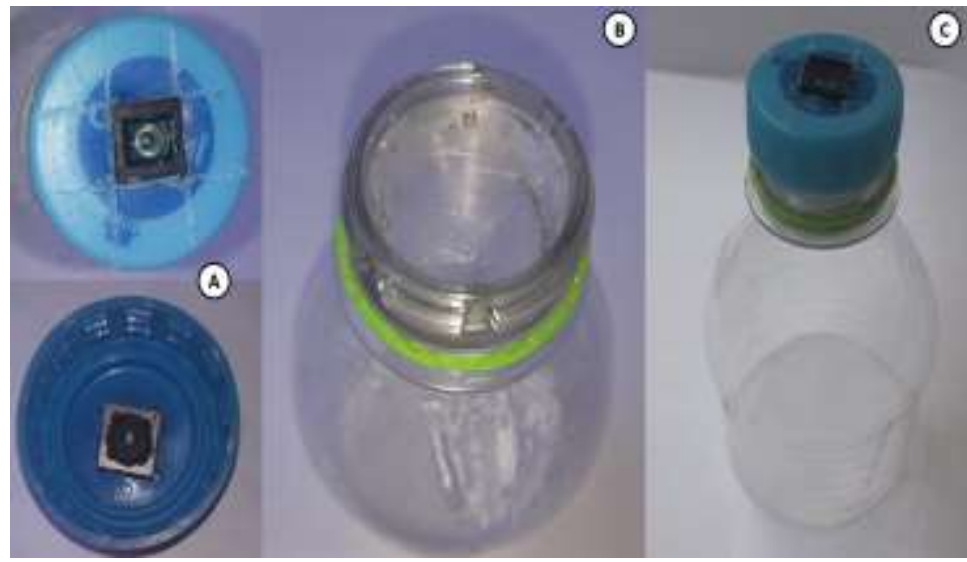

Figura 01: Versão do microscópio caseiro aprimorado a partir de Sepel, Rocha e Loreto (2011). A: lente derivada de lixo eletrônico fixada mecanicamente na tampa da garrafa pet em um furo de tamanho equivalente às suas dimensões; B: bocal da garrafa pet contendo placa fixa de resina de poliéster cristal transparente; C: microscópio caseiro completo. Fonte: autores.

Por questões de padronização e para melhor aproveitamento das oficinas ofertadas aos dois grupos avaliados neste estudo foram seguidas as seguintes etapas: 
1a aplicação de um questionário diagnóstico padronizado acerca dos conhecimentos prévios dos discentes sobre citologia;

2a introdução da oficina (exposição breve da história da microscopia e apresentação dos materiais necessários para a construção do microscópio caseiro);

3a montagem do microscópio caseiro pelos discentes (exceto a placa fixa de resina de poliéster cristal transparente) (Figura 02A);

4ạ Observação de amostras biológicas aplicando o microscópio adaptado (Figura 02B);

5a Reaplicação de questionário similar ao aplicado no início da oficina, porém mudando a disposição dos itens.

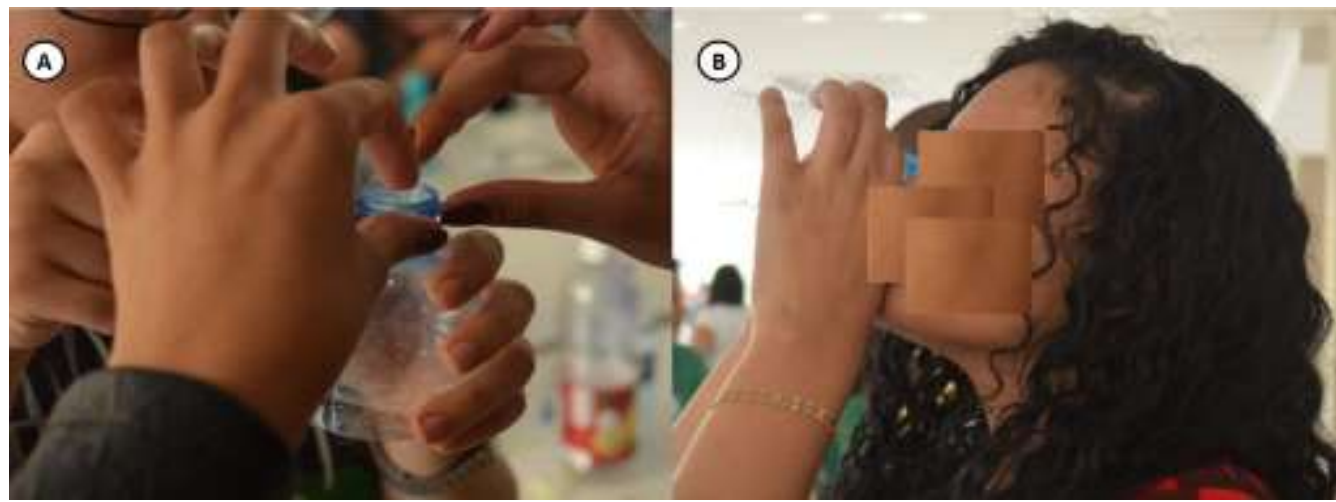

Figura 02: Atividades práticas realizadas em oficina ofertada para participantes do ConectalF 2019. A: montagem do microscópio proposto; B: observação de amostras biológicas. Fonte: autores.

Para os questionários, foram elaboradas quatro questões objetivas enfocando conceitos citológicos básicos (Quadro 01). Tais questões foram reavaliadas por professores com experiência no tema para evitar respostas tendenciosas.

Quadro 1: Questionário aplicado aos participantes das oficinas para avaliar a eficácia do microscópio aprimorado para ensinar fundamentos de citologia. Fonte: autores.

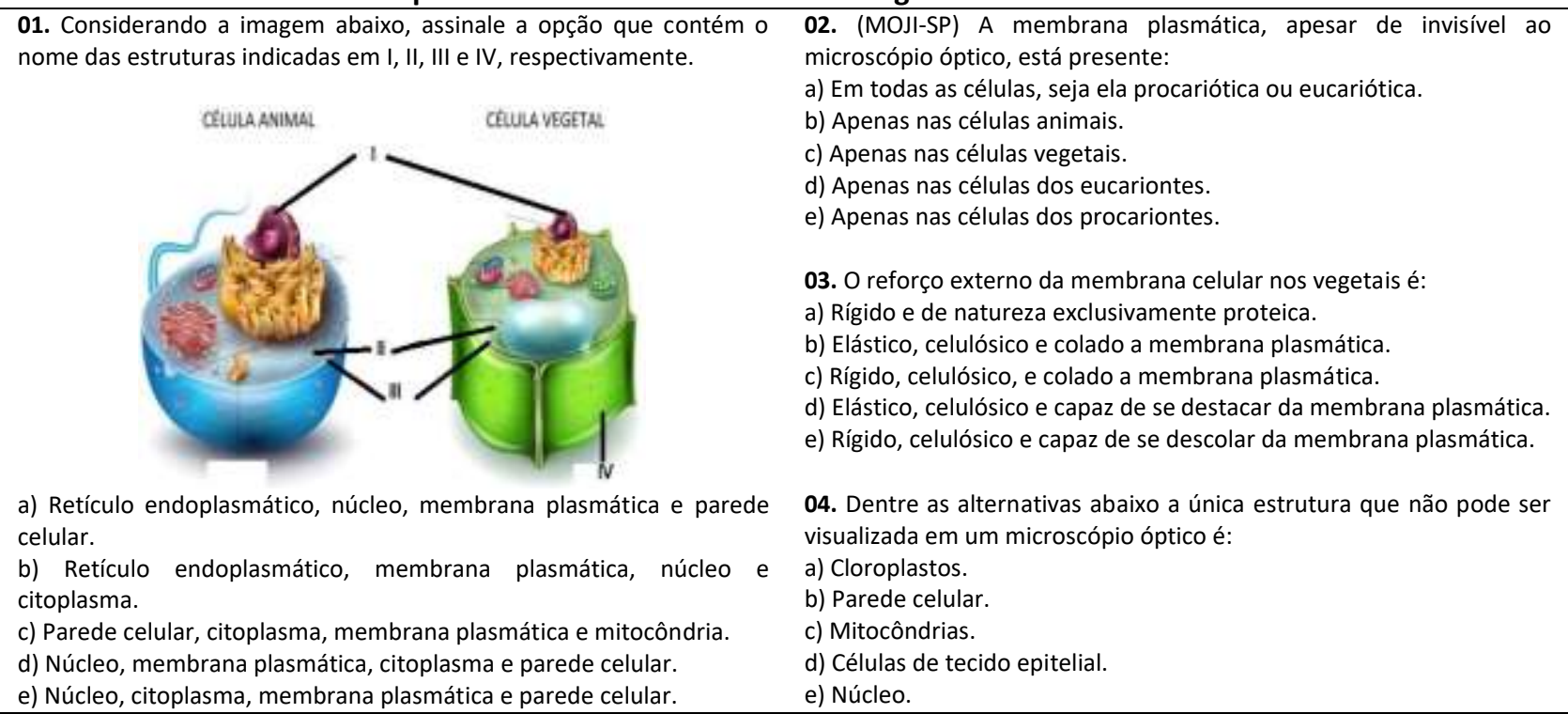

HOLOS, Ano 36, v.4, e9468, 2020 
O questionário foi aplicado antes e depois das oficinas para avaliar os efeitos pedagógicos das atividades desenvolvidas. Contudo, antes da sua primeira aplicação todos os participantes preencheram e assinaram um Termo de Consentimento Livre e Esclarecido (TCLE). Uma cópia do TCLE ficou com os autores desta pesquisa e a outra permaneceu com o pesquisado. Dessa forma, todas as atividades realizadas neste estudo foram fotografadas e as imagens resultantes foram usadas para uma avaliação qualitativa das atividades desenvolvidas.

Para medir a eficácia do microscópio adaptado para ensinar fundamentos de citologia, os resultados dos questionários foram usados para agrupar os participantes das oficinas em uma das seguintes categorias de rendimento (acertos) (elaboradas arbitrariamente): "0" (participantes que não acertaram nenhuma das quatro questões), " 1 " (participantes que acertaram uma questão), " 2 " (participantes com dois acertos), " 3 " (participantes que acertaram três questões) e " 4 " (participantes que acertaram todas as questões). Foram avaliadas eventuais diferenças entre o rendimento inicial e final em cada uma das duas oficinas. Para avaliar a similaridade no aprendizado entre os dois grupos, o total final de participantes considerados 0, 1, 2, 3 e 4 foi comparado.

O padrão de distribuição das categorias de rendimento antes e depois da execução das oficinas foi caracterizado mediante gráficos de distribuição de frequências. Variações na frequência de tais categorias foram acessadas usando a estatística do qui-quadrado (Tabela de Contingência). Todas as análises estatísticas foram rodadas no Past 2.16 (Hammer, Harper \& Ryan, 2001).

\section{RESULTADOS E DISCUSSÃO}

Os aprimoramentos feitos no microscópio caseiro original se mostraram funcionais e práticos durante a aplicação das oficinas. No microscópio original a lente é fixada em furo feito na tampa da garrafa com o auxílio de massa epóxi. Esse material demanda muito tempo de secagem e, por isso, é comum o deslocamento da lente durante o manuseio do microscópio. Tais problemas foram resolvidos com as adaptações aqui propostas, pois a fixação da lente diretamente na tampa em furo de dimensões compatíveis torna o posicionamento da lente mais preciso.

Outro problema no modelo original que dificulta a visualização imediata de amostras biológicas é a platina. Esse componente é feito de fita adesiva que se movimenta ao rosquear a tampa da garrafa para ajustar o foco. Como consequência, esse movimento desloca a amostra em análise causando problemas na sua visualização. Com a adaptação aqui proposta, ou seja, com a platina feita a partir de uma placa fixa de resina de poliéster cristal transparente, o manuseio da tampa contendo a lente não move a amostra em observação. Como resultado, a visualização das estruturas celulares ocorre mais facilmente em relação ao modelo original (Figura 03). Outra vantagem dessa resina é que é possível modelar a platina de modo a formar uma pequena 
"cavidade" na sua superfície. Dessa forma, a nova platina funciona como uma lâmina escavada onde é possível estudar amostras biológicas presentes em fluidos variados.

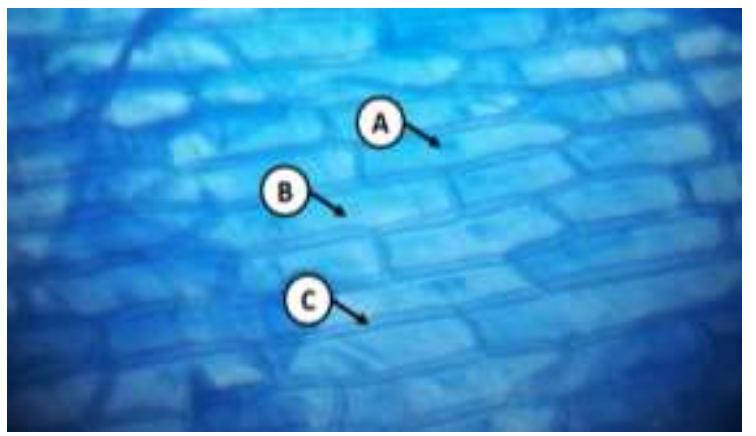

Figura 03: Células do catáfilo de Allium cepa observadas no microscópio adaptado. A: núcleo; B: citoplasma; C: parede celular + membrana plasmática. Fonte: autores.

Além disso, a resina poliéster cristal se mostrou um material muito resistente proporcionando durabilidade ao microscópio. O custo-benefício desse material também se mostrou satisfatório, pois com um litro de resina foi possível produzir os microscópios necessários a execução das duas oficinas, sobrando material para novas produções. Esses resultados estão de acordo com os pressupostos de Ribeiro (1955), o qual afirma que as construções de recursos didáticos improvisados ou com recursos mais baratos não devem ser vistas como uma solução de emergência, mas sim como uma alternativa que auxilie no desenvolvimento construtivo e criativo do estudante.

Tal desenvolvimento foi observado durante a execução das oficinas. Isso porque houve bastante participação e interesse dos alunos pelos procedimentos adotados. A natureza prática das oficinas certamente foi um dos fatores responsáveis pela mudança de comportamento descrita. Tais atividades práticas são reconhecidas por favorecer o aprendizado porque aumentam as chances de participação dos discentes nas atividades propostas, a interação entre eles, além de tornar dinâmica a atividade escolar (Martins, 2001). Segundo Piaget (1974), a utilização de objetos manipuláveis também facilita o ensino além de desenvolver a cognição discente. Dessa forma, materiais didáticos alternativos são necessários para auxiliar os docentes na execução de aulas práticas porque aumentam a conexão entre o objeto estudado e o cotidiano discente (Campos \& Cavassan, 2007), o que acarretará melhor compreensão dos conceitos abordados. Ações dessa natureza, portanto, podem contribuir para melhorar a educação científica de uma nação (Lopes \& Nunes, 2010).

Quanto a eficácia do microscópio adaptado para ensinar conceitos citológicos, houve variações de rendimento dentro e entre os grupos avaliados. No grupo representativo do EMI, houve aumento na quantidade de participantes nas categorias de maiores acertos após a aplicação da oficina, porém sem significância estatística $\left(X^{2}=4.95 ;\right.$ g.l. $\left.=4 ; p<0.3\right)$. Após a oficina, o total de participantes agrupados como " 0 " e " 2 " foi reduzido para $0 \%$ e $12,5 \%$, respectivamente; o total de "3" e " 4 ", por sua vez, aumentou para $25 \%$ e 31,25\%, respectivamente (Figura 04). Esses dados, portanto, sugerem que aulas práticas baseadas em recursos didáticos alternativos melhoraram o rendimento dos discente aqui avaliados. 


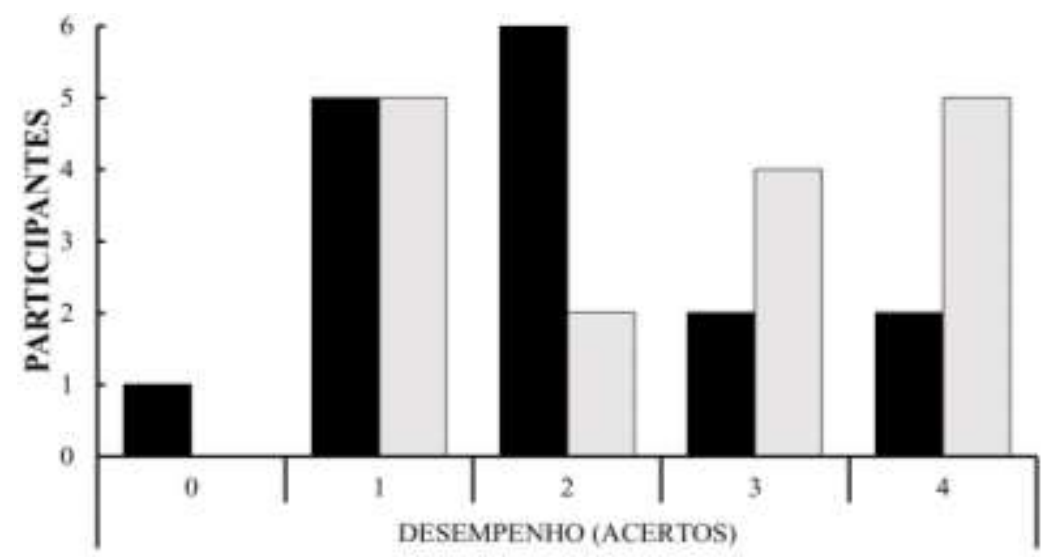

Figura 04: Categorias de desempenho antes (barras pretas) e depois (barras cinzas) de oficina ofertada a alunos do EMI. Dados coletados em agosto de 2019, no Campus Planaltina do IFB, Planaltina, Distrito Federal. Fonte: autores.

Quanto ao desempenho dos participantes do ConectalF 2019, a análise das categorias de rendimento também revelou aumento na quantidade de alunos nas categorias de maiores acertos após a aplicação da oficina, mas também sem significância estatística $\left(X^{2}=3.94 ; g . I .=3 ; p<0.33\right)$. Após a oficina, o total de participantes agrupados como "1" foi reduzido para 15\%; o total de "2" e "3", por sua vez, aumentou para $50 \%$ e $25 \%$, respectivamente. Não houve participantes enquadrados na categoria "4" (Figura 05). Esses dados mostram um aumento no número de acertos que também reforçam que aulas práticas baseadas em recursos didáticos alternativos melhoraram o rendimento dos discentes pesquisados.

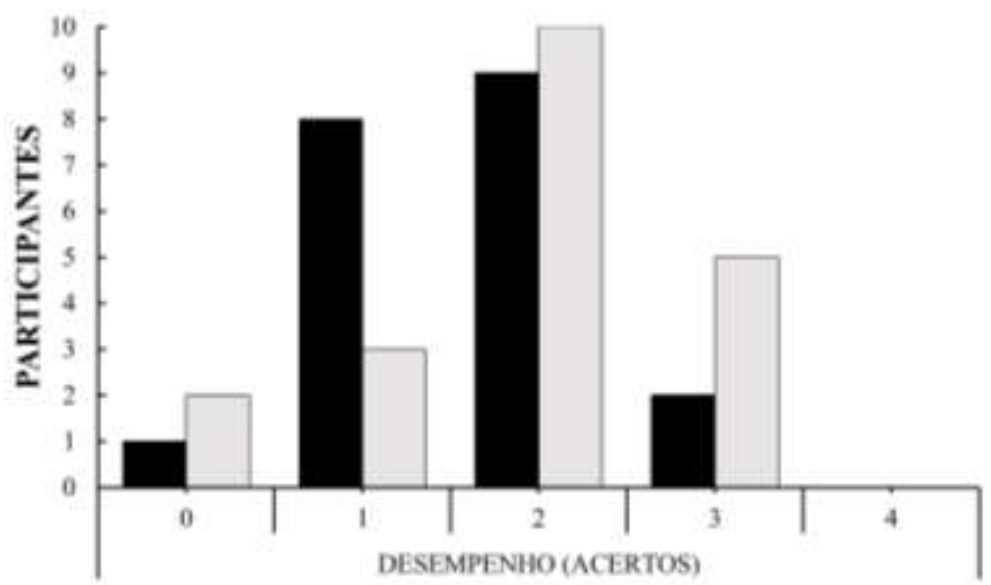

Figura 05: Categorias de desempenho antes (barras pretas) e depois (barras cinzas) de oficina ofertada para participantes do ConectalF 2019. Dados coletados em agosto de 2019 durante o ConectalF 2019, realizado no Campus Brasília do IFB, Distrito Federal. Fonte: autores.

Entre os dois grupos avaliados não houve similaridade de rendimentos. Isso porque a comparação entre as categorias de rendimento final dos participantes representativos do EMI e do ConectaIF 2019 mostrou maior rendimento dos participantes do EMI. Nesse caso, houve diferenças significantes $\left(X^{2}=12,7 ; g . l .=4 ; p<0.007\right)$ na distribuição dos participantes entre as categorias de rendimento provavelmente por causa de uma maior quantidade de participantes do EMI nas categorias de maior rendimento (Figura 06). 


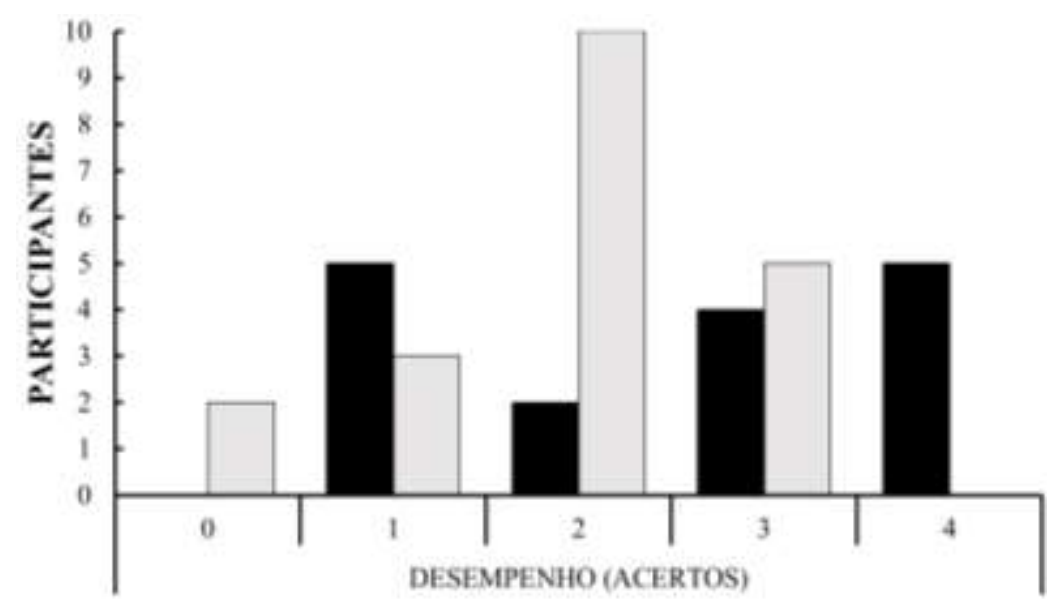

Figura 06: Categorias de desempenho final dos alunos do EMI (barras pretas) e participantes do ConectaIF 2019 (barras cinzas). Dados coletados em agosto de 2019 nos Campi Planaltina e Brasília do IFB, Distrito Federal. Fonte: autores.

Os dados quantitativos sugerem que os procedimentos pedagógicos aplicadas nas oficinas realizadas nesta pesquisa são mais eficientes quando utilizados em grupos mais homogêneos. É provável que a natureza heterogênea do grupo do Conectalf 2019 explique a variação de rendimento observado. Contudo, a logística do evento pode ter contribuído para tais resultados. Essa oficina acabou sendo realizada em local inadequado, o que resultou em dificuldades para a sua realização. A primeira dificuldade encontrada foi o espaço destinado a oficina, um espaço aberto, sem paredes ou algo que pudesse reduzir o ruído externo. A segunda dificuldade foi a existência de outras oficinas ocorrendo simultaneamente no mesmo espaço, todas separadas somente por fitas zebradas. O barulho produzido dificultou o entendimento das orientações passadas aos participantes e certamente contribuiu para o rendimento inferior desse grupo em relação aos alunos do EMI. Como consequência desse contexto, espera-se maior dispersão dos alunos, o que pode comprometer o desenvolvimento pedagógico das diferentes atividades aplicadas (Gonçalves, Silva \& Coutinho, 2009). Dessa forma, sugere-se pesquisas adicionais que avaliem grupos heterogêneos quanto aos aspectos pedagógicos proporcionados pelo microscópio caseiro aqui proposto, porém em ambientes apropriados (sem ruídos) para verificar sua real eficácia para ensinar conceito citológicos.

\section{CONSIDERAÇÕES FINAIS}

Os aprimoramentos aqui feitos no microscópio caseiro de Sepel, Rocha e Loreto (2011) aproximaram ainda mais esse recurso didático de um equipamento profissional, pois reproduziu mais eficientemente as funções das lentes, dos botões macro e micrométrico e da platina. Além disso, esse recurso didático melhorou a eficiência das aulas de citologia, resultando em maior número de acertos nos questionários respondidos, especialmente pelo grupo mais homogêneo avaliado em ambiente mais silencioso. 
Adicionalmente, foi observado maior envolvimento dos participantes pesquisados. Isso porque os participantes fizeram vários questionamentos e mostraram muita curiosidade e atenção durante as oficinas, além de interagir entre si e com o professor. Nesse aspecto, o recurso didático proposto foi eficiente e sua aplicação no contexto de sala de aula deve ser considerado pelos docentes que visam aprimorar suas aulas. Portanto, nós recomendamos a aplicação dos procedimentos pedagógicos aqui avaliados nos diferentes níveis de ensino para elevar a qualidade da educação científica brasileira.

\section{AGRADECIMENTOS}

Os autores agradecem a K.D. Schwarcz e M.L.O. Barbosa pela leitura e sugestões de melhorias deste manuscrito e ao Instituto Federal de Brasília (Campi Brasília e Planaltina) pelo apoio logístico. Esta pesquisa foi financiada pela Pró-reitoria de Extensão do Instituto Federal de Brasília.

\section{REFERÊNCIAS BIBLIOGRÁFICAS}

BRASIL. (2019). Resumo técnico - censo escolar 2018. Ministério da educação, Brasília, DF: INEP.

CAMPOS, S. S. P. \& CAVASSAN, O. (2007). A oficina de materiais recicláveis no ensino de ciências e nos programas de educação ambiental: refletindo sobre a prática educativa. Anais do VI Encontro Nacional de Pesquisa em Educação em Ciências (ENPEC), Florianópolis, Brasil.

FREITAS, L. A. M., BARROSO, H. F. D., RODRIGUES, H. G. \& AVERSI-FERREIRA, T. A. (2008). Construção de modelos embriológicos com material reciclável para uso didático. Bioscience journal, 24(1), 91-97.

FISCARELLI, R. B. O. (2007). Material didático e prática docente. Revista Ibero-Americana de Estudos em Educação, 2(1), 1-9.

GALLETI, S. R. (2003). Introdução a microscopia eletrônica. O Biológico, 65(1/2), 33-35.

GONÇALVES, V. S. B., SILVA, L. B. \& COUTINHO, A. S. (2009). Ruído como agente comprometedor da inteligibilidade de fala dos professores. Production Journal, 19(3), 466-476.

HAMMER, Ø., HARPER, D.A.T. \& RYAN, P.D. (2001). PAST: Paleontological Statistics Software Package for Education and Data Analysis. Palaeo Electronica, 4(1), 1-9.

LOPES, F. M. \& NUNES, A. N. (2010). Reutilização de materiais recicláveis para incentivo à educação ambiental e auxílio ao ensino didático de ciências em um colégio estadual de Anápolis-GO. Revista de Educação, 13(15), 87-103. 
MARTINS, J. S. (2001). O trabalho com projetos de pesquisa: do ensino fundamental ao ensino médio, 8.ed. Campinas: Papirus.

MARTINS, R. A. (2011). Robert Hooke e a pesquisa microscópica dos seres vivos. Filosofia e História da Biologia, 6(1), 105-142.

MORI, M. S., MOURA, D. A., VIANNA, J. B. \& FREITAS, S. R. S. (2016). Modelos didáticos no ensino de citologia: representação da anatomia celular por meio de pizzas. In: O Ensino de Ciências e Biologia no Amazonas: Experiências do PIBID no município de Tefé. Jundiaí, Paco Editorial.

PIAGET, J. (1974). Aprendizagem e Conhecimento. Rio de Janeiro, Equipe da Livraria Freitas Bastos.

PURVES, W. K., SADAVA, D., ORIANS, G. H. \& HELLER, H. C. (2009). Vida: a ciência da biologia. 8. ed., Porto Alegre, Artmed, $448 \mathrm{p}$.

RIBEIRO, J. C. (1955). O ensino experimental da Física no curso secundário. In: II Curso de aperfeiçoamento para professores de Física do ensino secundário. Atas do encontro IBECC. MEC-ITA, São Paulo.

ROTHBART, D. (2007). Philosophical instruments - minds and tools at work. University of Illinois Press.

SEPEL, L. M. N., ROCHA, J. B. T. \& LORETO, E. L. (2011). Construindo um microscópio II: bem simples e mais barato. Revista Genética na Escola , 6(2), 1-5.

SILVA, J. J., BALTAR, S. L. S. M. \& BEZERRA, M. L. M. B. Experimentação em ciências com o uso de um microscópio artesanal e corante alternativo. Experiências em Ensino de Ciências, 14(1), 344-352.

SIMMONS, J. (2002). Os 100 maiores cientistas da história: uma classificação dos cientistas mais influentes do passado e do presente. 4. ed., Rio de Janeiro, Bertrand Brasil, 584 p.

SOGA, D., JUNIOR, R.D.P., UENO-GUIMARÃES, M.D. \& MURAMATSU, M. (2017). Um microscópio caseiro simplificado. Revista Brasileira de Ensino de Física, 39(4), e4506.

VALÉRIO, M. \& TORRESAN, C. (2017). A invenção do microscópio e o despertar do pensamento biológico: um ensaio sobre as marcas da tecnologia no desenvolvimento das ciências da vida. Revista de Ensino de Biologia da SBEnBio, 10(1), 125-134.

WALLAU, G. L., ORTIZ, M. F., RUBIN, P. M., LORETO, L. E. S. \& SEPEL, L. M. N. (2008). Construindo um microscópio, de baixo custo, que permite observações semelhantes às dos primeiros microscopistas. Revista Genética na Escola, 3(2), 8-10.

\section{COMO CITAR ESTE ARTIGO:}

Silva, R.G.S., Roque, F. (2020). Aprimoramento de um microscópio caseiro e sua eficácia para ensinar citologia básica. Holos, 36(4), 1-12. 


\section{SOBRE OS AUTORES}

\section{RAMON GOMES DOS SANTOS SILVA}

Professor de Biologia da Secretaria de Estado de Educação do Distrito Federal; Graduado em Ciências Biológicas (Licenciatura) pelo Instituto Federal de Educação, Ciência e Tecnologia de Brasília (IFB-Campus Planaltina). E-mail: ramongomesss2@gmail.com

ORCID ID: https://orcid.org/0000-0003-4353-6254

\section{FRANCISCO ROQUE}

Professor do Instituto Federal de Educação, Ciência e Tecnologia de Brasília (IFB-Campus Recanto das Emas). Graduado em Ciências Biológicas (Bacharelado/Licenciatura) pela Universidade de Brasília (UnB). Mestre em Ecologia. Doutor em Biologia Animal. E-mail: francisco.roque@ifb.edu.br ORCID ID: https://orcid.org/0000-0002-9306-0365

Editor(a) Responsável: Francinaide de Lima Silva Nascimento Pareceristas Ad Hoc: Marcelo Távora e Fábio Portella Corrêa de Oliveira

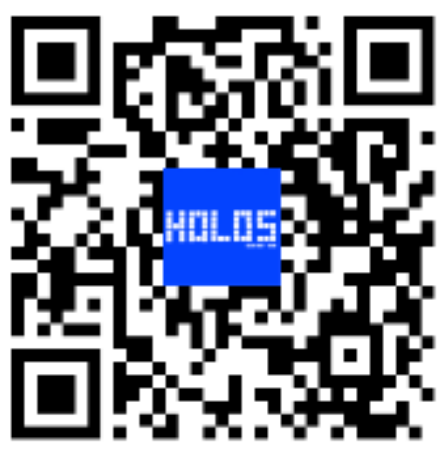

Recebido: 27 de janeiro de 2020 Aceito: 04 de maio de 2020

Publicado: 01 de julho de 2020 